\title{
Combination of Sonodynamic and Photodynamic Therapy against Cancer Would Be Effective through Using a Regulated Size of Nanoparticles
}

\author{
N. Miyoshi ${ }^{1, *}$, S. K. Kundu ${ }^{1,2}$, T. Tuziuti ${ }^{3}$, K. Yasui ${ }^{3}$, I. Shimada ${ }^{4}$, Y. Ito ${ }^{5}$ \\ ${ }^{1}$ Department of Tumor Pathology, Faculty of Medical Sciences, University of Fukui, Japan \\ ${ }^{2}$ Department of Pharmacy, Jahangirnagar University, Bangladesh \\ ${ }^{3}$ National Institute of Advanced Industrial Science and Technology (AIST), Japan \\ ${ }^{4}$ Department of Forensic Medicine, Faculty of Medicine, University of Fukui, Japan \\ ${ }^{5}$ Laboratory of Bioseparation Technology, Biochemistry and Biophysics Center, National Heart, Lung, and Blood Institute, USA
}

Copyright $(\mathcal{C} 2016$ by authors, all rights reserved. Authors agree that this article remains permanently open access under the terms of the Creative Commons Attribution License 4.0 International License

\begin{abstract}
Nanoparticles have been used for many functional materials in nano-sciences and photo-catalyzing surface chemistry. The titanium oxide nanoparticles will be useful for the treatment of tumor by laser and/or ultrasound as the sensitizers in nano-medicine. We have studied the combination therapy of photo- and sono-dynamic therapies in an animal tumor model. Oral-administration of two sensitizers titanium oxide, $0.2 \%-\mathrm{TiO}_{2}$ nanoparticles for sono-dynamic and $1 \mathrm{mM} 5$-aminolevulinic acid for photodynamic therapies have resulted in the best combination therapeutic effects for the cancer treatment. Our light microscopic and Raman spectroscopic studies revealed that the titanium nanoparticles were distributed inside the blood vessel of the cancer tissue (1-3 $\mu \mathrm{m}$ sizes). Among these nanoparticles with a broad size distribution, only particular-sized particles could penetrate through the blood vessel of the cancer tissue, while other particles may only exhibit the side effects in the model mouse. Therefore, it may be necessary to separate the optimum size particles. For this purpose we have separated $\mathrm{TiO}_{2}$ nanoparticles by countercurrent chromatography with a flat coiled column $(1.6 \mathrm{~mm}$ ID) immersed in an ultrasonic bath $(42 \mathrm{KHz})$. Separation was performed with a two-phase solvent system composed of 1-butanol-acetic acid-water at a volume ratio of $4: 1: 5$ at a flow rate of $0.1 \mathrm{ml} / \mathrm{min}$. Countercurrent chromatographic separation yielded fractions containing particle aggregates at 31 and $4400 \mathrm{~nm}$ in diameter.
\end{abstract}

Keywords Titanium Dioxide $\left(\mathrm{TiO}_{2}\right)$ Nanoparticles, 5-aminolevulinic Acid (5-ALA), Countercurrent Chromatography (CCC), Raman Spectrum Microscope, Sono-dynamic Therapy (SDT), Photo-dynamic Therapy

\section{Introduction}

Cancer could be treated as the most complicated disease in the medical science and for this reason scientists of different parts of the world are still trying their level best to achieve a full control on this chaotic pathological condition. Cancer cell can camouflage due to its resembling features with the host cell and therefore tracking down its abnormal characteristics seems to be the most challenging parts to succeed in its treatment. Another miserable situation in cancer cells is their unique and unpredictable molecular modifications through point mutations, translocations, fusions, and other aberrations even for the similar category of cancer in different individuals [1-5]. At present, however on many cases of cancer treatment scientists have managed quite satisfactorily through designing appropriate targeted therapy alone or with other conventional cancer treatment modalities like surgery, radiation therapy, and/or chemotherapy, etc. [6-10]. But the treatment spectrum of combination therapy is quite large and less expensive. Hence, scientists put their effort on this field in a great extent now a days and trying to generate effective as well as safer combination therapy using different means of combinations among surgery, radiation therapy, and/or chemotherapy, etc. In many cases drug-cocktails or sequenced therapeutic combinations of natural, synthetic or semi-synthetic chemotherapeutic agents have shown a great promise for treating cancer more effectively by avoiding or overcoming a very usual phenomenon of single drug induced resistance capability of the cancer cells. [11-15] In our study we have used the combinations of two different physical inputs of sound and light for activating a combined anticancer sensitizer, namely $\mathrm{TiO}_{2}+5$-ALA, more effectively. 
Over the last 30 years sonodynamic therapy (SDT) has been built up and N. Miyoshi also has a very good research track on this technology regarding its application on cancer model [16-18]. Sonodynamic activity actually creates the acoustic cavitation effect in presence of some particles to generate hydroxyl radicals or singlet oxygen species into the biological environment and also enhance the cytotoxic property of some compounds. Another advantageous point is that it can be applied for deeper portion of the tissue and thereby it might be very much helpful on striking the root of the localized cancer. Hence, without any surgical operation this therapy can produce a high impact on inhibiting the tumor growth. Moreover, the multiple or frequent application is quite harmless with this kind of therapy.

On the other hand, photodynamic therapy (PDT) has also been regarded as a very effective means of cancer treatment mainly for the superficial origins like skin, esophagus, oral cavity, etc. [19-22] PDT, using a photosensitizer and laser emission, has been applied quite successfully in Japan for the last 15 years against the early cancers of esophagus, lung, stomach and cervix of the uterus. For the head and neck cancer also it has shown a good promise [23-26]. PDT is also very much safe in respect of adverse effects to the other biological parts around the cancer region. But, penetration depth of the light is limited and that's why in case of advanced stage of a cancerous proliferation PDT often produces less success.

To overcome the aforementioned limitations of these two treatment modalities, we have carried out for the first time a combination therapy of PDT and SDT for the treatment of cancer model tissue. For this purpose, we have chosen titanium oxide, $\quad \mathrm{TiO}_{2}$ nanoparticles and 5-ALA (5-aminolevulinic acid) as the higher affected precursor of sensitizers for cancers. Here the 5-ALA directed the movement of $\mathrm{TiO}_{2}$ to the target tumor tissue. Recently, nanoparticles have been being used for many functional materials in nano-sciences [27-31] and photo-catalyzing surfaces [32-46]. The $\mathrm{TiO}_{2}$ particles (crystal size 5-6 nm which were used for UV-cut raw materials in a make-up) were previously used as the sono-sensitizer for the production of $\mathrm{OH}$ radicals by the ultrasound irradiation due to the cavitation effect with the particles in the water $[18$, 47-49].

From different studies it is also quite evident that movement or penetration of the nanoparticles depends largely on their particle size and agglomeration tendency with the surrounding biological components when applied endogenously [50-51]. Both intra- and inter-particular adherence might hinder their free or desired movement into the blood and thereby to the tissue. From this point of view, we have tried to separate different particles of 5-ALA/ $/ \mathrm{TiO}_{2}$ aggregates with the help of a revolutionary liquid-liquid partition chromatography system, namely countercurrent chromatography (CCC), which utilizes a liquid stationary phase to avoid the sample loss due to irreversible adsorption or denaturation caused by the solid support used in conventional chromatographic module like HPLC or TLC [52-54]. In this method solutes are partitioned between mobile or stationary phases according to their partition coefficients, whereas, the aggregated particles are usually accumulated in the interphase of the immiscible droplets and eluted earlier. In our present study, we have generated smaller droplets in the CCC column using ultrasonic irradiation to improve the partitioning of aggregates of 5-ALA/ $\mathrm{TiO}_{2}$.

Through our present study we also put our effort to understand the distribution pattern of the $\mathrm{TiO}_{2}$ in the tumor tissue to get some impression regarding the necessity of appropriate and regulated size of nanoparticles to be used as more effective sensitizers for this kind of physical input oriented modality of the anticancer treatment.

\section{Experimental}

\subsection{Chemical Materials}

5-Aminolevulinic acid hydrochloride salt (5-ALA; purity: 99.9\%) used in this study was presented from Cosmo Oil Co, Ltd. (Tokyo, Japan). The nanoparticle of titanium oxide $\left(\mathrm{TiO}_{2}\right)$ used in this study were also given from Tayca Co. Ltd. (Osaka, Japan) as the $20 \%$ colloidal solution of titanium dioxide $\mathrm{TiO}_{2}$ phosphate salt crystal (TKS-203: $\mathrm{Ti}_{3}\left(\mathrm{PO}_{4}\right)_{4}$; the particle size is $5-6 \mathrm{~nm}$ which were used for a make-up as the raw materials). 1-Butanol of HPLC grade was purchased from Fisher Scientific, Park Lawn, NJ, USA, and acetic acid of analytical grade from Mallinckrodt, MO, USA. H \& E histological staining solution was purchased from Katayama Chemical Engineering, Osaka, Japan.

\subsection{Ultrasound Probe and the Instruments System: [Figure 1]}

Ultrasound Probe (P) was assembled with a Cooler (C), an Amplifier (A) and a Generator (G) as a systematic instrument. The ultrasound irradiation instrument system at $1 \mathrm{M}$-hertz (MHz) had been built up according to the advice of Dr. Shinichiro Umemura of the Central Institute of Hitachi Ltd. Co. (Tokyo, Japan).Especially, the irradiation was adjusted by a special small probe (P: the diameter was $25 \mathrm{~mm}$ ) of ultrasound for the tumor model tissue (the diameter was within $10 \mathrm{~mm}$, the irradiation time was 10 $\mathrm{min})$ of BALB-c-nu/nu strain nude mice (20 g) during more than 5 years of a collaboration research with the institute as shown in Figure 1. 


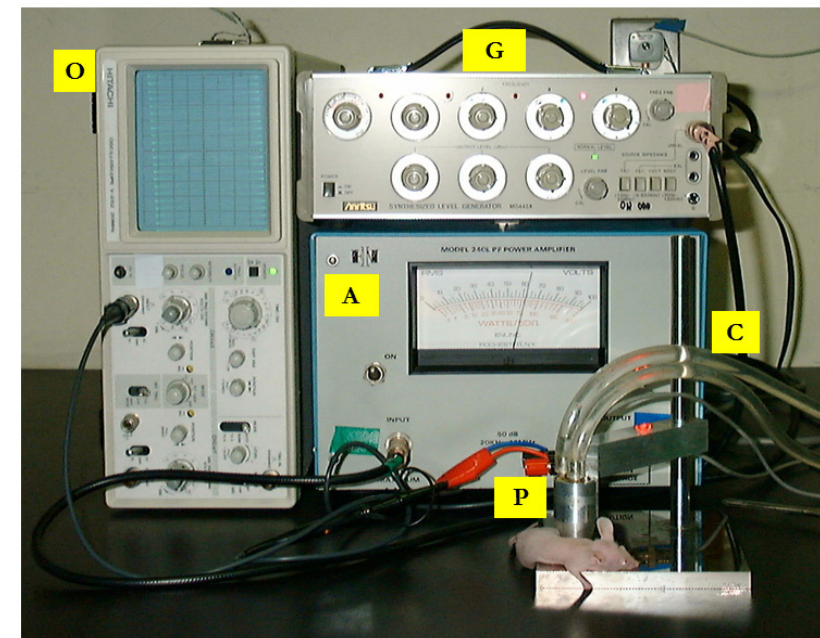

Figure 1. Instrumental arrangements. Instruments of ultrasound of 1 $\mathrm{MHz}$ irradiation $(10 \mathrm{~min})$ for each experimental SCC tumor models bearing $\mathrm{C}_{3} \mathrm{H} / \mathrm{He}$ mouse. (P) was ultrasound probe for mouse. The probe was presented from Hitachi Basic Institute against the mouse experiments. (A) was the power amplifier (ENI Ltd. Co., Model was 240L) and (G) was the synthesized level generator (Anritsu Ltd. Co., MG 442A type) looking with an oscilloscope (Hitachi Ltd. Co., V-252 type, 20MHz). (C) was a cooling device for the probe $(\mathrm{P})$ by flowing water from the water pipes. The frequency of $1 \mathrm{MHz}$ was optimized with looking the oscilloscope to be to the largest shaking of the needle hand controlled by the changing the fine knob of the frequency of the $\mathrm{Hz}$.

\subsection{Animal Experiments: [Figure 2]}

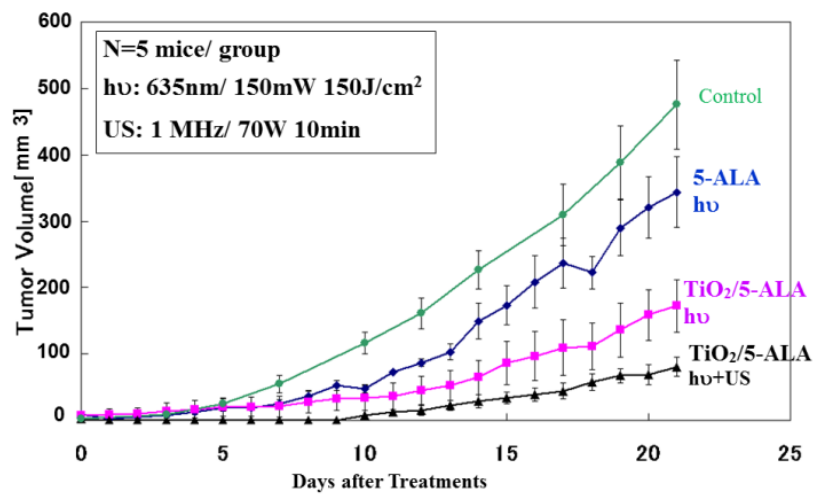

Figure 2. Growth Curves of SCC Tumor against the Time (days) after Treatments. (Control) group was without any treatments. (5ALA, hv) group was irradiated $150 \mathrm{~mW} / \mathrm{cm}^{2}$ for $1,000 \mathrm{sec}\left(150 \mathrm{~J} / \mathrm{cm}^{2}\right)$ at $635 \mathrm{~nm}$ of LD laser $5 \mathrm{hrs}$ after oral administration of $1 \mathrm{M} 5$-ALA saline (final concentration was $10 \mathrm{mM})$. (5-ALA/ $/ \mathbf{T i O}_{2}$, hv) group was irradiated $150 \mathrm{~mW} / \mathrm{cm}^{2}$ for $1,000 \mathrm{sec}\left(150 \mathrm{~J} / \mathrm{cm}^{2}\right)$ at $635 \mathrm{~nm}$ of LD laser $5 \mathrm{hrs}$ after oral administration of $1 \mathrm{M}$ 5-ALA saline (final concentration was $10 \mathrm{mM}$ ) with $20 \%$ nanoparticle (the final concentration was $0.2 \%$ ). $\left(\mathbf{5 A L A} / \mathbf{T i O} \mathbf{O}_{2}\right.$, $\mathbf{h v}+$ US) group was irradiated $150 \mathrm{~mW} / \mathrm{cm}^{2}$ for $1,000 \mathrm{sec}\left(150 \mathrm{~J} / \mathrm{cm}^{2}\right)$ at 635 $\mathrm{nm}$ of $\mathrm{LD}$ laser and irradiated for $10 \mathrm{~min}$ of ultrasound of $1 \mathrm{MHz}$ (Figure 1) $5 \mathrm{hrs}$ after oral administration of $1 \mathrm{M} 5$-ALA saline (final concentration was $10 \mathrm{mM}$ ) with $20 \%$ nanoparticle (the final concentration was $0.2 \%$ ), respectively.. The average tumor volume of 5 tumors was plotted on each curve in each group.

A $\mathrm{C}_{3} \mathrm{H} / \mathrm{He}$-strain mouse (CLEA-Japan, Inc.., Tokyo, Japan) bearing subcutaneously-implanted (the 2x10E5 cells/0.1 ml RPMI medium were implanted under the skin on the back) squamous cell carcinoma (SCC) was given the oral administration of $\mathrm{TiO}_{2} / 5$-ALAparticles suspension. After 4 hours, the tumor tissue $\left(5 \times 7 \times 7 \mathrm{~mm}^{3}\right)$ was removed, and the frozen-sectioned slice $(10 \mathrm{~m})$ of the raw tumor tissue was subjected to a Raman microscopic study as well as histological studies with hematoxylin and eosin $(\mathrm{H} \& \mathrm{E})$ staining after fixation with $70 \%$ ethanol aqueous solution. The histological studies were made from the peripheral portion of the tumor.

Animal experiments were done according to the rule and guideline of the animal ethics committee in National University of Fukui to use anesthesia regents (Isoflurane-inhalation, Abbott-Japan Ltd. Co., Tokyo, Japan) at the treatment of mice and at the endpoints $\left(\mathrm{CO}_{2}\right.$ gas, Uno-Sanso Ltd. Co., Fukui, Japan).

The number of experimental mice in the each 4 groups was 5. The tumor sizes (the approximation volume of elliptical body $=[\mathrm{a} \times \mathrm{b} \times \mathrm{c}] / 6$ ) were measured every day for 21 days after the treatments using an elaborate digital caliper (Type: Absolute Solar Digimatic Caliper, Mitutoyo Ltd. Co., Niigata, Japan). The average volume of the 5 tumors was calculated to plot on the growth curve with the standard deviations (SD) as shown in Figure 2.

\subsection{Cavitation Measurement Changing by Ultrasound Frequency: [Figure 3]}

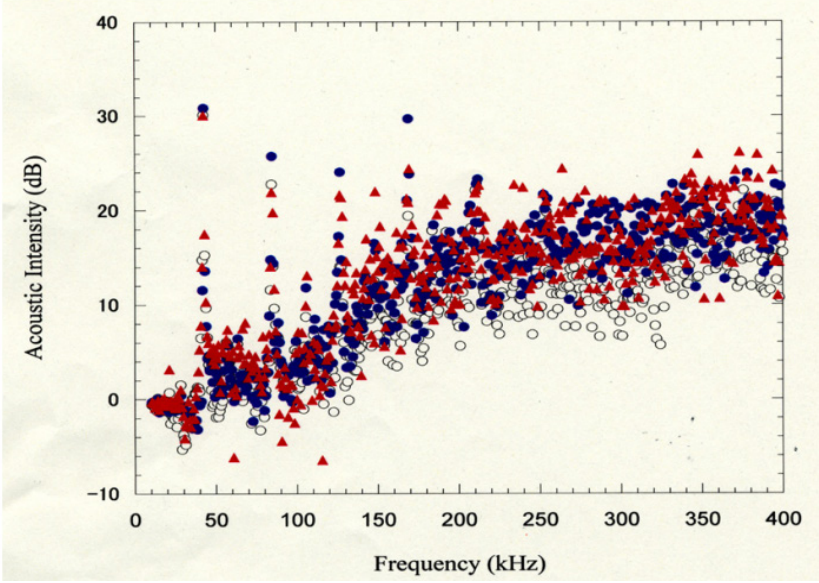

Figure 3. Cavitation noise spectra. The base lines of the cavitation at (US only), $\left(\mathrm{US}+\mathrm{TiO}_{2}\right)$ and at $\left(\mathrm{US}+\mathrm{TiO}_{2}+\mathrm{ALA}\right)$ groups were normalized at the average (AVR) intensities of 5 times experiments, respectively. Spectrum Analyzer (Tektronix 3026 type, Tektronix Japan Ltd. Co., Tokyo, Japan), Probe (Hydrophone) of the cavitation (TC4038 type, RESOV Ltd. Co., Slangerup, Denmark), Source of ultrasonic irradiation (1510J-MT type, Branson Ultrasonics Ltd. Co., Connecticut, USA), The $1 \mathrm{ml}$ sample aqueous solution was irradiated in the degassed water bath. The hydrophone probe was set in the sample tube and the cavitation signal (acoustic noise) was detected by the spectro-analyzer.

Cavitation noise spectra against 3 kinds of solutions: The driving frequency was about $4 \mathrm{kHz}$. The base lines [open circle] of the cavitation at (US only), $\left(\mathrm{US}+\mathrm{TiO}_{2}\right)=$ [closed black circle] and at $\left(\mathrm{US}+\mathrm{TiO}_{2}+\mathrm{ALA}\right)=[$ closed red triangle $]$ groups were normalized at the average intensities of 5 times experiments, respectively as shown in Figure 3. 
Spectrum Analyzer (Tektronix 3026 type, Tektronix Japan Ltd. Co., Tokyo, Japan), Probe (Hydrophone) of the cavitation (TC4038 type, RESOV Ltd. Co., Slangerup, Denmark), Source of ultrasonic irradiation (1510J-MT type, Branson Ultrasonics Ltd. Co., Connecticut, USA), The $1 \mathrm{ml}$ sample aqueous solution was irradiated in the degassed water bath. The hydrophone probe was set in the sample tube and the cavitation signal (acoustic noise) was detected by the spectrum analyzer.

\subsection{ESR (Electron Spin Resonance) Measurement with Spin-trapping Method: [Figure 4]}

The typical 1:2:2:1 spectrum pattern of spin-trapping agent, $150 \mathrm{mM}$ DMPO (5,5'-dimethyl-1-pyroline-N-oxide, LABOTEC, Ltd. Co., Tokyo, Japan)-OH radical adduct, was observed by ESR (Model-JES-RE1X, JEOL Co. Ltd., Tokyo, Japan) measurement in 2 different solutions,

(1) closed circle: saline solution, and (2) open circle: $0.2 \%-\mathrm{TiO}_{2}$ in $1 \mathrm{mM}$ 5-ALA saline solution after the irradiation $(50 \mathrm{~W})$ by ultrasound at $42 \mathrm{kHz}$ as shown in Figure 4. The sample solutions $(1 \mathrm{ml})$ were sonicated for 1 , 2, 5, $10 \mathrm{~min}$ in an ultrasonic field in $13 \times 100 \mathrm{~mm}$ disposable pyrex tubes (Corning Inc., Corning, NY, USA) exposed to air and fixed in the center of a sonication bath (Bransonic 1510, frequency $=42 \mathrm{kHz}, 50 \mathrm{~W}$ ). The power input was determined $50 \mathrm{~W}$ for comparison, $5 \mathrm{~min}$ of sonolysis of $1.0 \mathrm{ml}$ of aqueous argon-saturated Fricke dosimeter solution [55] (ferrous sulfate $[1 \mathrm{mM}], \mathrm{NaCl}[10$ $\mathrm{mM}]$ and $\mathrm{H}_{2} \mathrm{SO}_{4}[0.4 \mathrm{M}]$ ) under the same conditions gave an absorbance reading of $0.23+/-0.01$ (mean of five determinations $+/-\mathrm{SD}$ ) at $302 \mathrm{~nm}$ in a $1 \mathrm{~cm}$ quartz cell. The power input was determined calorimetrically as $50 \mathrm{~W}$ for the radical detection experiments.

\subsection{Raman Spectrum Microscope Mapping Image: [Figures 5 and 6]}

Raman spectrum microscope (MRS-1000 MTS-model, JASCO Ltd. Co., Tokyo, Japan) was used for the measurement of Raman shift spectrum (Figure 5) and the mapping image $\left(1.45 \times 1.45 \mathrm{~mm}^{2}\right)$ on the cryo-sectioned slice of the raw tumor tissue of the model mouse at 2738 $\mathrm{cm}^{-1}$ peak area excited at $785 \mathrm{~nm}$ as same methods as reported by our previous reports $[56,57]$.

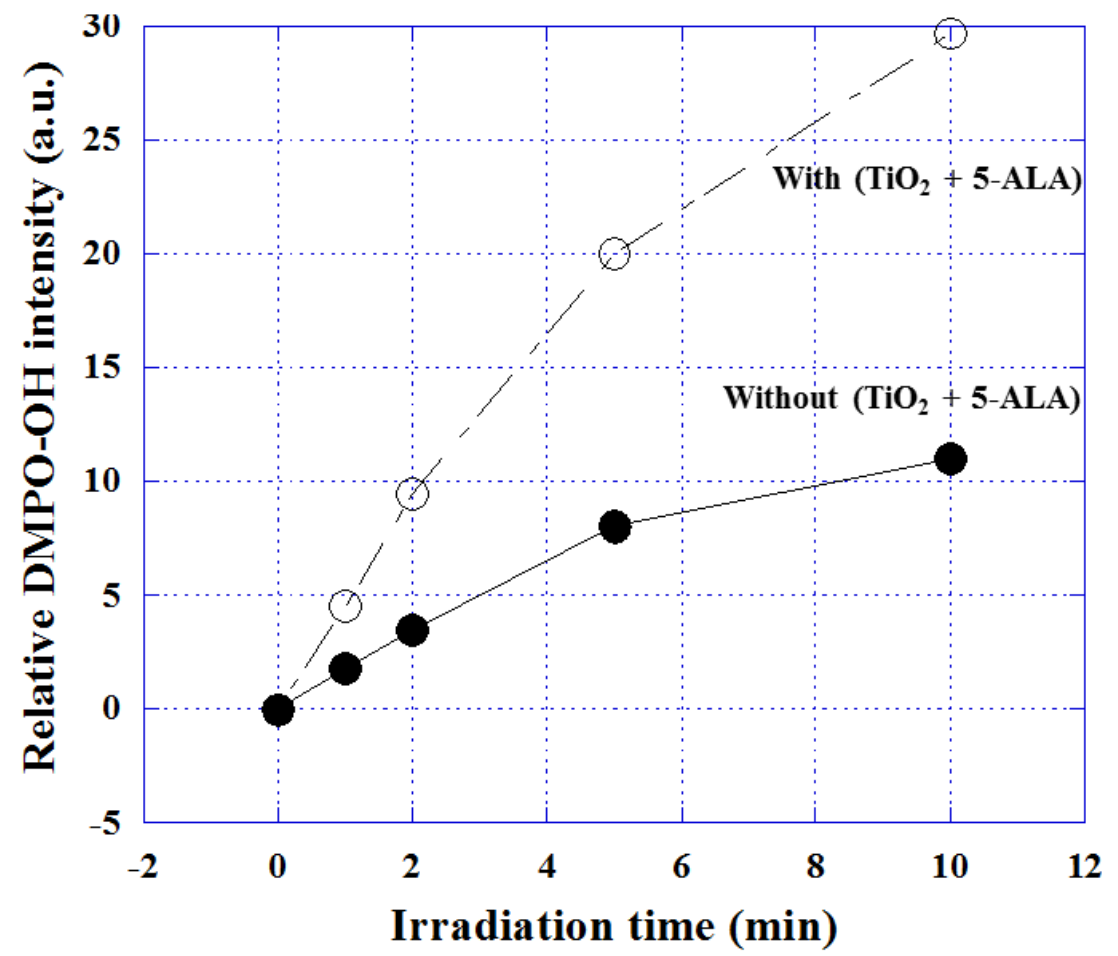

Figure 4. Relative DMPO-OH radical adduct intensity dependent on irradiation time of ultrasound by ESR measurement with a spin trapping agent, DMPO. Open circle was the intensities irradiated with $\mathrm{TiO}_{2}$ nanoparticles +5 -ALA, and closed circle was those of without nanoparticles and without 5-ALA, respectively. The conditions of ESR (JES-RE3XR type, JEOL Ltd., Tokyo, Japan) measurement of the OH radicals were shown as following: (1) Power=10 mW; (2) Field=335.4 mT/G +/- $5 \mathrm{mT} / \mathrm{G}$; (3) Sweep Time=2 min; Mod.=9.427 GHz; (4) Receiver Gain=7.9 x100; (5) Time Const.=0.01 sec. The ratio of the typical peak intensity $(1: 2: 2: 1)$ against the standard marker $\left(\mathrm{Mn}_{2}{ }^{+}\right)$were compared for the irradiation times of ultrasound (Bransonic 1510, frequency $=42 \mathrm{kHz}, 50 \mathrm{~W}$ ). 


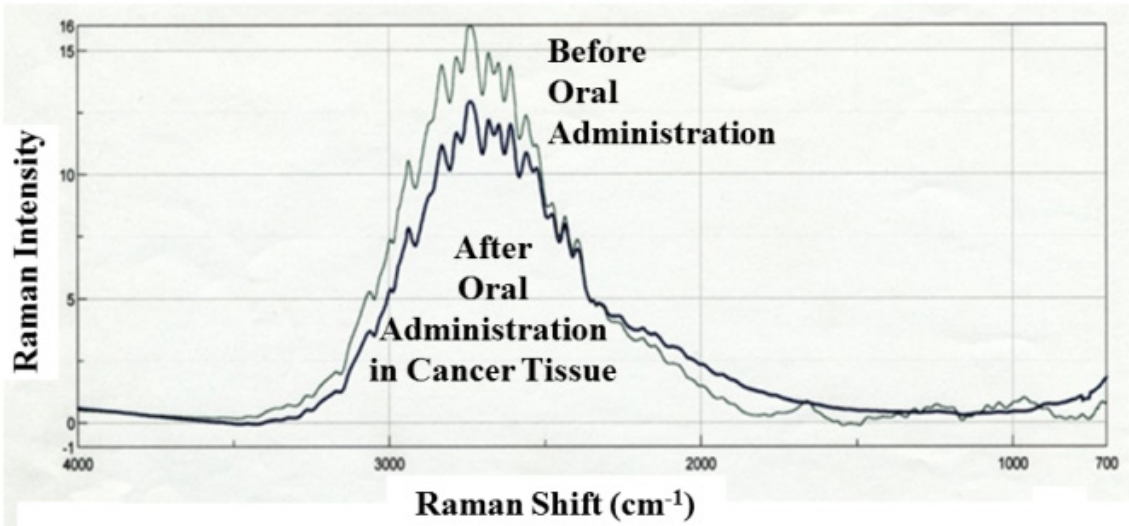

Figure 5. Raman spectra of the $0.2 \%-\mathrm{TiO}_{2}$ nanoparticles with 5-ALA before and after the oral administration. The thin line was the spectrum of the sample before administration. The thick line was the spectrum in the tumor tissue of the sample after the administration.

The Raman mapping image was compared with the $\mathrm{H} \& \mathrm{E}$ staining image of the next sliced tissue of the same tumor tissue as shown in Figure 6.

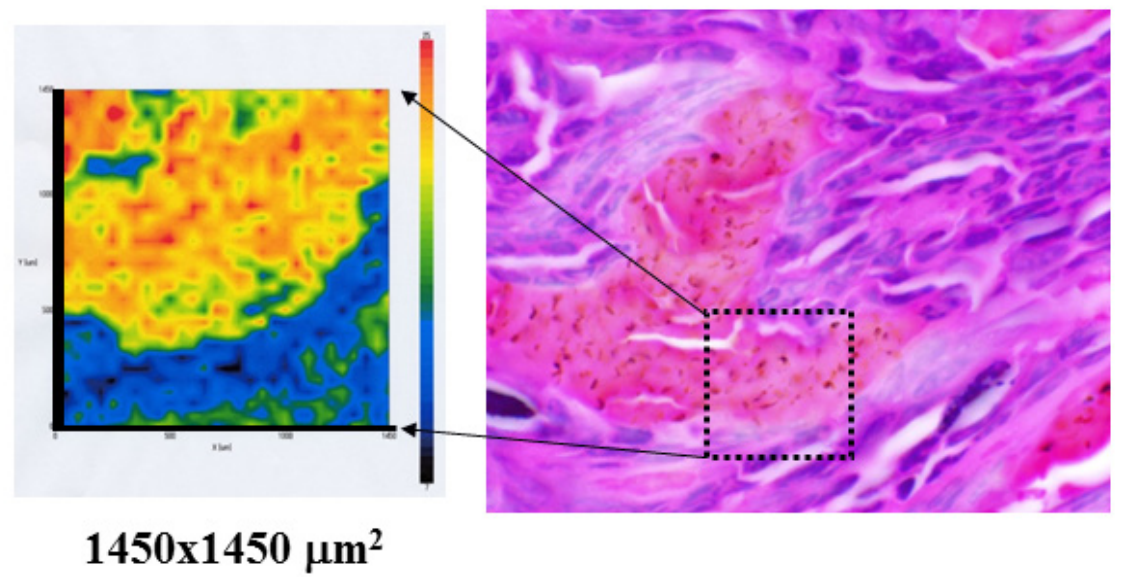

Figure 6. Histological H \& E staining image (a) and a Raman mapping image against $\mathrm{Ti}_{3}\left(\mathrm{PO}_{4}\right)_{4}$ nano-particle (b) of the squamous cell carcinoma (SCC) tumor model tissue. The Raman image was made by mapping for the Raman scatter absorption intensities of the peak area at $2738 \mathrm{~cm}^{-1}$.

\subsection{Partition of $\mathrm{TiO}_{2}$ Nanoparticles before Purification: [Figure-7]}

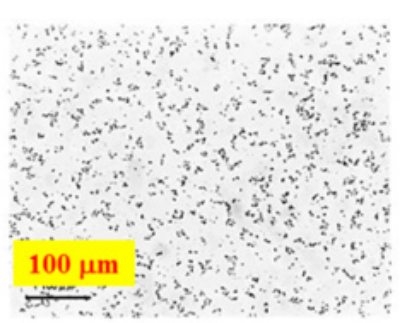

(a) $\mathrm{TiO}_{2}$

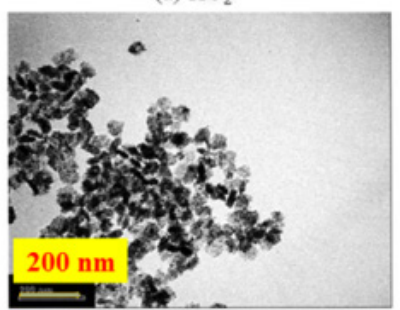

(c) $\mathrm{TiO}_{2}$

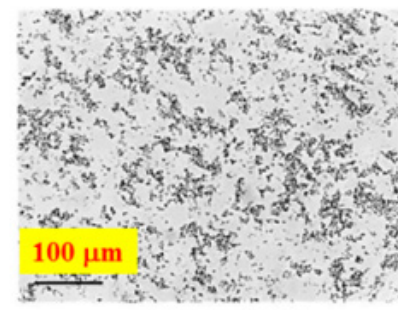

(b) $\mathrm{TiO}_{2}+5-\mathrm{ALA}$

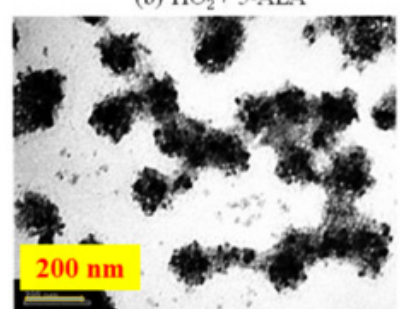

(d) $\mathrm{TiO}_{2}+5$-ALA
$\mathrm{BuOH} / \mathrm{AcOH} / \mathrm{H}_{2} \mathrm{O}$

$(4: 1: 5, v / v)$

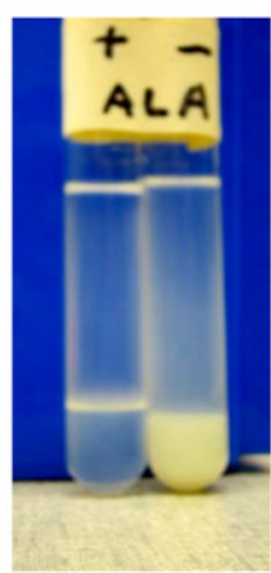

Figure 7. Interaction of the $2 \%-\mathrm{TiO}_{2}$ nanoparticle with $1 \mathrm{mM} 5-\mathrm{ALA}$ in the mixed solution of 1-buthanol : acetic acid : water $=4: 1: 5$ after treatment of ultrasound for $10 \mathrm{~min}$. The nano-particles were observed by a transmit electron microscope (TEM; H-7650 type, HITACHI Ltd., Co., Tokyo, Japan) as shown in photographs $\mathrm{C}$ and D. Under the light microscope, these two solutions of nano-particles suspension with (C, A) and without (D, B) 5-ALA was observed as showing photographs (A and B). Comparing photographs of A with $\mathrm{B}$ and $\mathrm{C}$ with $\mathrm{D}$, it is evident that there are some interactions of 5-ALA molecules with the nano particles. 
The partition of $\mathrm{TiO}_{2}$ nanoparticles was carried out in the test tubes and observed with different microscopes on the mixed solution $\left(\mathrm{BuOH} / \mathrm{AcOH} / \mathrm{H}_{2} \mathrm{O}=4: 1: 5\right)$ after treated by sonication at $42 \mathrm{kHz}(70 \mathrm{~W})$ for $5 \mathrm{~min}$. A micro-photometer (Type: BH2, Olympus Ltd. Co., Tokyo, Japan) and a transmission electron microscope (TEM; Type: H-7650, Hitachi, Ltd., Co., Tokyo, Japan) were used to observe the nanoparticles interaction with 5-ALA.

\subsection{Apparatus and Procedure: [Figure 8]}

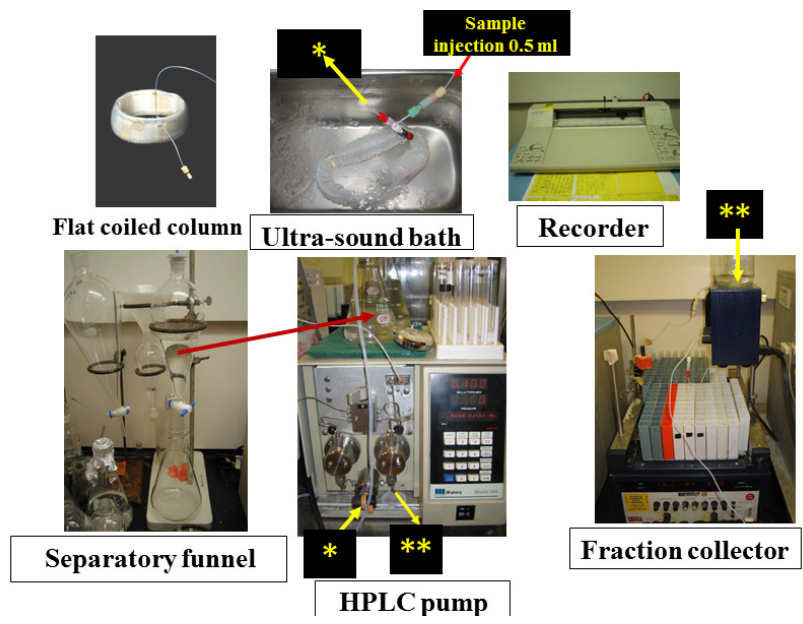

Figure 8. Diagram of the separation system of CCC instruments. The separation system was constructed by 5 parts (Sample injection of $5 \mathrm{ml}$ in an ultra-sound both, Separation funnel, HPLC pump, Fraction collector, Recorder). The length of column tube was $12 \mathrm{~m}$ and the inside diameter was $1.6 \mathrm{~mm}$, the total volume was $33 \mathrm{ml}$. The ultra-sound bath was a product from Bransonic Co. Ltd., Eagle Rd., Danbury, CT 06813, USA. HPLC pump was obtained from Water Ltd. Co. product of type 510, the fraction collector was produced from Ultrorac Ltd. Co. in Sweden (Model: Ultrac Type-7000).

The CCC system used to separate the nanoparticles interacted with 5-ALA by sonication. The separation column was prepared by winding about $12 \mathrm{~m}$ long, $1.6 \mathrm{~mm}$ ID PTFE (polytetrafluoroethylene) tubing (Zeus Industrial Products, Orangeburg, SC, USA) onto a circular plastic strip (width: $5 \mathrm{~cm}$; thickness: $1 \mathrm{~mm}$ ) forming a flat coil with ca $33 \mathrm{ml}$ in capacity. It was immersed in an ultrasound bath (42 KHz) (Branson-1510R-MT Type, Bransonic Inc., Danbury, CT, USA) in a vertical position during the separation. The effluent was pumped with a Waters HPLC pump and monitored with a UV monitor (Uvicord SII, LKB Instruments, Bromma, Sweden) at $280 \mathrm{~nm}$. The chromatogram was recorded with a strip-chart recorder (Pharmacia, Stockholm, Sweden).

A polar two-phase system composed of 1-butanol-acetic acid-water at a 4:1:5 volume ratio was prepared. The solvent mixture was thoroughly equilibrated in a separator funnel and the two phases were separated shortly before use. The separation of $\mathrm{TiO}_{2}$ particles was performed in the Laboratory of Bio-separation Technology, NHLBI, NIH as follows: the column was first completely filled with the upper organic stationary phase followed by sample injection through the sample port. Then, the aqueous mobile phase was eluted through the column at a flow rate of $1 \mathrm{ml} / \mathrm{min}$, while the effluent was continuously monitored at $280 \mathrm{~nm}$ with the UV detector and fractionated into test tubes at 4 $\mathrm{ml} /$ tube. The temperature of the ultrasound bath was manually controlled at $22-26^{\circ} \mathrm{C}$ by adding ice as shown in Figure 8.

\subsection{Analysis of CCC Fractions: [Figure 9]}

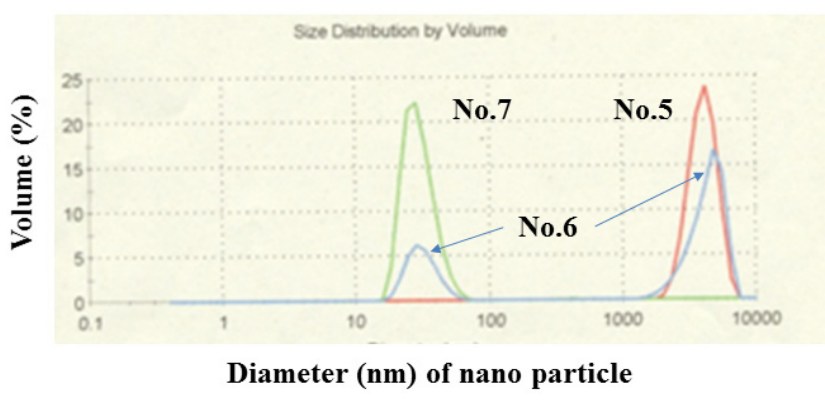

Figure 9. The distribution of $2 \%-\mathrm{TiO}_{2}$ nanoparticles of the fraction No. 5 , 6, and 7 (saline) separated by CCC. Nanoparticle Distribution Analyzer (Zetasizer Nano ZS type, Malvern Instruments Ltd, Worcestershire, UK). A $0.5 \mathrm{ml}$ sample solution fractioned by CCC system was measured in the analyzer within $5 \mathrm{~min}$.

The distribution of $\mathrm{TiO}_{2}$ nanoparticles mixed with 5-ALA, fraction No. 5, 6, and 7 ( $0.5 \mathrm{ml}$ saline solution), separated by CCC were measured by a scatter method instrument [Zetasizer Nano ZS-type, Malvern Institutes Ltd., Worcestershire, UH] in the National Institute of Advanced Industrial Science and Technology (NAIST) in Nagoya, Japan as shown in Figure 9. The measured sample solutions of the fraction No. 5, 6, and 7 were suspended in $0.5 \mathrm{ml}$ saline solution.

\section{Results and Discussion}

We had been studied of PDT using 5-ALA as a precursor, protoporphyrin-IX (Pp-IX) of hem [59] which had used as a photosensitizer and a fluorescent indicator of cancer margin of glioblastoma during the neurosurgical operation in clinical uses of Japan. Pp-IX has a good affinity of the tumor tissue. We had the plan to use 5-ALA as the carrier of nanoparticles into the tumor tissue if the affinity interactions of them would be given after the modification by the sonication of them with ultrasound. It will be very important thing in the biological nano-sciences to apply using the nanoparticles for the cancer treatment. Hence, we started to build up the instrument of ultrasound irradiation against the tumor model as shown in Figure 1. The mixed solution of $0.2 \%$-titanium oxide particles and $10 \mathrm{mM}$ 5-ALA were oral-administrated into the model mice immediately after the sonication $(42 \mathrm{kHz}, 70 \mathrm{~W})$ for $5 \mathrm{~min}$ at $3 \mathrm{hr}$ before the combined treatments of SDT and PDT as shown in Figure 2. 


\subsection{Combination Therapy of PDT and SDT: [Figure-2]}

The SCC (Squamous Cell Carcinoma) tumour tissues were irradiated by laser light $\left(635 \mathrm{~nm}, 150 \mathrm{~mW} / \mathrm{cm}^{2}\right.$ for $\left.1,000 \mathrm{sec}=150 \mathrm{~J} / \mathrm{cm}^{2}\right)$ before the ultrasonic treatment $(1$ $\mathrm{MHz}, 70 \mathrm{~W}$ for $10 \mathrm{~min}$ ) using the instrument of Figure 1. (1) Green curve indicates the control group without any treatments and it highlights the exponential growing of the tumour sizes. (2) Blue curve represents single PDT after 3 $\mathrm{hr}$ of the oral administration of $0.1 \mathrm{mM}$ 5-ALA saline solution $(0.2 \mathrm{ml})$ without $0.2 \%$ titanium oxide particles. There was a mild anti-tumour effect by PDT. (3) Pink curve shows single PDT after $3 \mathrm{hr}$ of the oral administration of $0.1 \mathrm{mM} \mathrm{5-ALA} \mathrm{saline} \mathrm{solution}(0.2 \mathrm{ml})$ immediately mixing with $0.2 \%$ titanium oxide particles suspended in a phosphate aqueous solution diluted with saline solution. It was considered that the titanium nano-particles may trigger in the anti-tumour effect in 5-ALA aqueous solution as the nano-particles enhance the photosensitizing effects, which might be caused by the stability in the excited Pp-IX (porphyrin-IX) and effectively transform the excited electron energy or the charge in the excited state. (4) Black curve denotes the combination of PDT and SDT treatments, where SDT after PDT, after $3 \mathrm{hr}$ of the oral administration with $0.1 \mathrm{mM} 5$-ALA saline solution $(0.2 \mathrm{ml})$ immediately mixing with $0.2 \%$ titanium oxide particles suspended in a phosphate aqueous solution diluted with saline solution.

It was observed that there was a synergistic anti-tumour effect of PDT and SDT treatments in the aforesaid fashion. Whereas, only SDT didn't show any remarkable anti-tumour activity when applied with 5-ALA alone and less than that of PDT when applied after administering 5-ALA $/ \mathrm{TiO}_{2}$ mixture (data not shown). Although the missing of the data of only the $\mathrm{TiO}_{2}$ particle with laser light, it was considered that the anti-tumor effect would be a small one as the laser light of $635 \mathrm{~nm}$ would not be absorbed by the particle.

\subsection{Cavitation Measurement: [Figure-3]}

Cavitation noise spectra against 3 kinds of solutions have been shown in Figure 3. The base lines of the cavitation at ultrasound (US) only [open circle], combination of US and $\mathrm{TiO}_{2}\left[\right.$ closed black circle] and combination of US, $\mathrm{TiO}_{2}$ and ALA [closed red triangle] groups have been normalized at the average intensities of 5 times experiments, respectively.

The average inside area of these curves of 10 times measurements was compared between those 3 different solutions. It was found that the area in the case of titanium oxide particles only was enhanced by $28 \%$, and in the case of the presence of nano-particles with 5-ALA aqueous solutions the area was enhanced by $36 \%$ at $2 f_{0}\left(2^{\text {nd }}\right.$ harmonics) and (3/2) $f_{0}$ (ultra-harmonics) where the fundamental frequency $\left(f_{0}\right)$ was about $40 \mathrm{kHz}$. Accordingly, the yield of the active oxygen species was expected to be increased by these cavitation effects with the collateral presence of 5-ALA and nanoparticles in aqueous solution, even though the frequency and the medium of the tumor tissue were different from that $(1 \mathrm{MHz})$ in animal experiment conditions.

\subsection{ESR Measurement of the Active Oxygen Species produced by the Acoustic Cavitation Effects in Aqueous Solutions: [Figure-4]}

The typical 1:2:2:1 spectrum pattern of DMPO-OH radical adduct was observed by ESR measurement in 2 different solutions, (1) closed circle: saline solution only and (2) open circle: $0.2 \%-\mathrm{TiO}_{2}$ in $1 \mathrm{mM}$-ALA saline solution. It was considered that the yield of the radical adduct of DMPO-OH was increased with the irradiation time of ultrasound in both solutions at $42 \mathrm{kHz}$. Especially, the increasing speed was very different, finally, the adduct intensity at $10 \mathrm{~min}$ in the case of the mixed solution with nanoparticles was 3 times larger than that of the control solution although the frequencies were different from the animal treatments. This enhancement of the $\mathrm{OH}$ radical production would be correlated with the cavitation intensity by ultrasound irradiation with nano-particles as shown in Figure 4.

\subsection{Distribution of $\mathrm{TiO}_{2}$ Particle Aggregates in the Tumor Tissue Observed by Raman Spectrum Microscope: [Figures-5 and -6]}

The mixed aqueous solution of $0.2 \%-\mathrm{TiO}_{2}$ particles with $10 \mathrm{mM}$ 5-ALA was oral administrated to the mouse bearing implanted squamous cell carcinoma (SCC). Then, $3 \mathrm{hr}$ later the tumor tissue was removed and embedded into optimum cutting temperature compound medium to freeze at $-20^{\circ} \mathrm{C}$. The frozen sample was sliced at $10 \mu \mathrm{m}$ thickness and observed by a Raman spectrum microscope (Figure 5). The sliced tumor tissue was also studied with an optical microscope after $\mathrm{H} \& \mathrm{E}$ histological staining. In Figure 6, the numerous large (3-5 $\mu \mathrm{m}$ size) aggregates of $\mathrm{TiO}_{2}$ particles are seen around blood vessels of the interstitial tumor tissue from the $\mathrm{H} \& \mathrm{E}$ stained image.

The Raman spectra of the $0.2 \%$ titanium oxide particles in aqueous solution and in tumor tissue were observed before and after the administration of $1 \mathrm{mM}$ 5-ALA saline solution. However, there is no prior data against the $\mathrm{TiO}_{2}$ powder particles in the Raman's data bank. We observed that the peaks in the aqueous solution were spread between 2,300 and $3,000 \mathrm{~cm}^{-1}$. The main peak was present at 2,738 $\mathrm{cm}^{-1}$ as same shapes before and after the administration although we have also observed the absorption peak of the nano particle at $353 \mathrm{~cm}^{-1}$ in far-infrared region in the tumor tissue. As the probe spectral peak was found, we could make the image of the distribution of the particles inside the tumor tissue using the mapping method of Raman microscopy as shown in Figure 6.

Histological H \& E staining (Right-side image) and a 
Raman mapping image against $\mathrm{TiO}_{2}$ nanoparticles (Left-side image) of the squamous cell carcinoma (SCC) tumor model tissue are shown in Figure 6. The Raman image was made by mapping for the Raman shift absorption intensities of the peak area at $2738 \mathrm{~cm}^{-1}$ as shown in Figure 5. There were 21,025 mapping points $(145 \times 145)$ for $12 \mathrm{hrs}$. The Raman spectrum microscopic observation documented that the distributed $\mathrm{TiO}_{2}$ particles aggregate at the blood vessel in the tumor tissue.

\subsection{Partition of $\mathrm{TiO}_{2}$ Nanoparticles before Purification: [Figure-7]}

Distribution of $\mathrm{TiO}_{2}$ nanoparticles in the two-phase solvent system composed of 1-butanol-acetic acid-water with and without adding 5-ALA is illustrated in Figure 7. Both test tubes were treated by ultra-sound irradiation (sonication at $42 \mathrm{kHz}, 70 \mathrm{~W}$ for $5 \mathrm{~min}$ ). As clearly shown, the particles were almost completely distributed into the lower aqueous phase without 5-ALA in the solvent system whereas they were totally distributed at the interface when 5-ALA was added to the solvent system. It was considered that a week interaction of the nanoparticles with 5-ALA to be aggregated after the sonication as shown in the both microscopes (compared with $\mathrm{a}$ and $\mathrm{b}, \mathrm{c}$ and $\mathrm{d}$ in photo-microscope, in TEM). The diameter of $\mathrm{TiO}_{2}$ nanoparticles was $50 \mathrm{~nm}$ and that of the aggregate with 5-ALA was about $135 \mathrm{~nm}$ which was 2.7 times lager in the diameter from the TEM images (c and d).

The CCC separation of the $\mathrm{TiO}_{2}$ particles was performed with the above solvent system by injecting the sample suspension containing 5-ALA at a concentration of $1 \mathrm{mM}$ as shown in Figure 8 instrument.

\subsection{Apparatus and Procedure: [Figure 8]}

Figure 8 shows CCC apparatus and the procedure of aggregated nanoparticles, separator funnel, flat coiled column, ultra-sound bath, HPLC pump, fraction collector, and recorder parts. The sample solution of $0.5 \mathrm{ml}$ was injected before the lower phase from the column $(\rightarrow *)$ to through the HPLC pump $(* \rightarrow)$. From the HPLC pump $(\rightarrow * *)$ was connected with absorbance detector $(* * \rightarrow)$ at $280 \mathrm{~nm}$ to fractionate to the collector as shown in Figure 8. The separation was completed in 2 hours.

\subsection{Mechanism of Particle Preparation in CCC: [Figure-10]}

Figure 10 schematically shows hydrodynamic process of the two phases in a flat coiled column consisting of two units where the upper phase (clear) is retained in the left loop and the lower mobile phase (shaded) mostly occupies the space in the right loop in each unit. Application of ultrasonic irradiation produces constant carryover of the stationary phase in the mobile phase, resulting in formation of multiple droplets of one phase in the other phase. These droplets carry particle aggregates according to their affinity on the interface. Consequently, larger particles which have higher affinity can move through the column faster than smaller particles which have less affinity at the interface, resulting in a chromatographic separation according to the size of the particles. Without ultra-sonic irradiation the aggregates would stay at the pair of interface of the solvent systems formed on the top and bottom of the loop and remain in the column much longer time without clear separation. These large molecular will be not able to be separated by high performance liquid chromatography (HPLC).

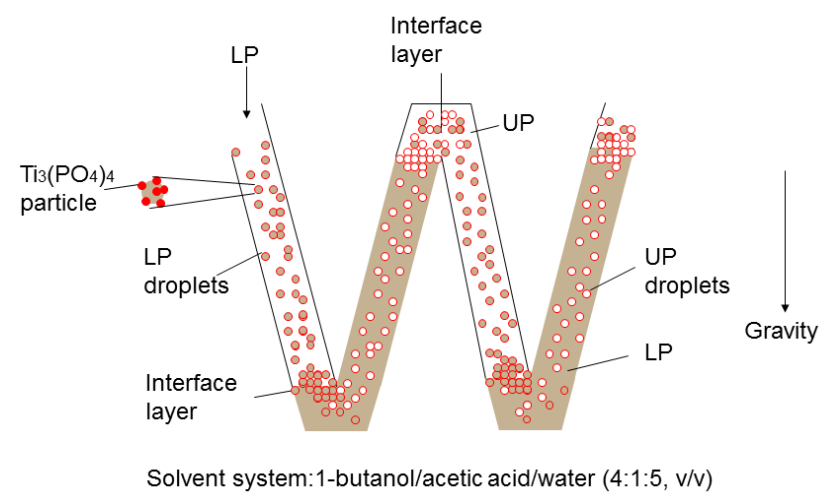

Figure 10. A scheme of the separation for the aggregates of $2 \%-\mathrm{TiO}_{2}$ nano-particles with $1 \mathrm{mM} 5$-ALA in the mixed solvent system (1-butanol/acetic acid/water $=4 / 1 / 5)$. UP $=$ Upper phase of the mixed solution, $\mathrm{LP}=$ Lower phase of the mixed solution.

\subsection{Separation of $\mathrm{TiO}_{2}$ Particles: [Figure 10]}

The effluent of CCC separation was collected in 20 fractions for 2 hours which were pooled into three fractions No. 5, 6 and 7 according to the chromatograph (the chart has not shown). Due to the carryover of the stationary phase, the chromatogram shows multiple small peaks, while fractions No. 5 and 7 showed distinct single peaks. As clearly shown in the diagram, fraction 5 (red) contained the particle aggregates at $4400 \mathrm{~nm}$ in diameter and fraction 7 (green) contained the smaller particle aggregates at $31 \mathrm{~nm}$ in diameter, while fraction No. 6 (blue) was a mixture of these two fractions. It indicates that the larger particle aggregates are eluted earlier apparently due to their stronger affinity at the interface between the two phases.

It is of a great interest that only two sizes of aggregates were collected, one around $31 \mathrm{~nm}$ and the other, $4400 \mathrm{~nm}$ in diameter. This suggests that the original $\mathrm{TiO}_{2}$ particles form only two kinds of stable aggregates with 5-ALA. Among these fractions, No. 7 might be suitable for the further animal studies by scaling-up of the present separation system. For the animal application the fractions should be degassed to eliminate 1-butanol and acetic acid followed by the precipitation with ethanol and dispersed in saline prior to the administration to animal tumor model. 


\section{Conclusions}

The efficacy of nano-scale titanium dioxide has been checked against different cancer models [59-60], viral infections [61], bacterial strains [62] as well as for delivering drug to the targeted gene of the damaged cells [63-64]. However, due to the possible toxic effects on the living organisms wide application of $\mathrm{TiO}_{2}$ nanoparticles has been reduced in some extent also [65]. But according to various studies it has been postulated that toxic effects of $\mathrm{TiO}_{2}$ nanoparticles depends on their shape, size, agglomeration state, surface chemistry and above all concentration [66-68]. The most vulnerable tendency of nanoparticles is agglomeration especially under the physiological conditions like neutral $\mathrm{pH}$, water solubility, presence of salts and proteins, etc. [50-51]. Some studies also proved that the use of phosphate buffer can reduce the cytotoxic properties of $\mathrm{TiO}_{2}$ nanoparticles. Thus, for our study we have chosen the nanoparticles of $\mathrm{Ti}_{3}\left(\mathrm{PO}_{4}\right)_{4}$, which after being absorbed converted into $\mathrm{TiO}_{2}$ to explore its activity as the sono-sensitizer. Moreover, treated mice were under regular observation for checking any sorts of abnormalities like irritation, shin hypersensitivity reactions, breathing problems, unusual weight loss/gain, etc. We didn't observe any such unusual problems.

Thus our study suggests a great possibility of using titanium oxides along with 5-ALA for applying into the localized tumor tissue (Raman mapping image) even in the advanced stage. Sonodynamic followed by photodynamic therapy (SDT and PDT) can help to get a reasonable anti-tumor effect because the ultrasound can penetrate deeper into the cancer tissue compared with the laser light (635 nm). Our studies also suggested that countercurrent chromatography (CCC) might be a great choice for collecting pure aggregates of the $\mathrm{TiO}_{2}+5$-ALA for the combination therapy of SDT and PDT while avoiding any unpredictable adverse effects due to the agglomeration of the nanoparticles destined into the tumor tissue.

\section{Acknowledgements}

The author (N. M.) wishes to express many thanks to Dr. Prof. Shinichiro Umemura for their academic supports. The study was supported by a Grant-in-Aid for Scientific Research and Special study Area: Photo-functional Surface from Japan Society for the Promotion of Science (JSPS). Furthermore, the author likes to acknowledge the support by the Stiftelsen fund of Sweden-Japan Cooperative Research Foundation in Kanazawa (Japanese Research Chief: Prof. H. Hisazumi). Finally, the author would like to thank for the companies (Hitachi Ltd. Co., Tokyo; Tayca Co. Ltd., Osaka, and Cosmo Oil Co. Ltd., Tokyo) and these researchers to support various kinds of instruments and reagents used in this research.

\section{REFERENCES}

[1] Yates, L. R.; Campbell, P. J. Evolution of the cancer genome. Nat. Rev. Genet. 2012, 13, 795-806.

[2] Garraway, L. A.; Lander, E. S. Lessons from the cancer genome. Cell 2013, 153, 17-37.

[3] Soon W. W.; Hariharan, M.; Snyder, M. P. High-throughput sequencing for biology and medicine. Mol. Syst. Biol. 2013, 9,640

[4] Nik-Zainal, S.; Alexandrov, L. B.; Wedge, D. C.; Van Loo, P.; Greenman, C. D.; Raine, K.; Jones, D.; Hinton, J.; Marshall, J.; Stebbings, L. A.; et al. Mutational processes molding the genomes of 21 breast cancers. Cell 2012, 149, 979-993.

[5] Shendure, J.; Lieberman Aiden, E. The expanding scope of DNA sequencing. Nat. Biotechnol. 2012, 30, 10841-1094.

[6] Yoshino, T.; Hasegawa, Y.; Takahashi, S.; Monden, N.; Homma, A.; Okami, K.; Onozawa, Y.; Fujii, M.; Taguchi, T.; de Blas, B.; et al. Platinum-based chemotherapy plus cetuximab for the first-line treatment of Japanese patients with recurrent and/or metastatic squamous cell carcinoma of the head and neck: results of a phase II trial. Japanese J. Clin. Oncol. 2013, 43, 524-531.

[7] Vermorken, J. B.; Stöhlmacher-Williams, J.; Davidenko, I.; Licitra, L.; Winquist, E.; Villanueva, C.; Foa, P.; Rottey, S.; Skladowski, K.; Tahara, M.; et al; Cisplatin and fluorouracil with or without panitumumab in patients with recurrent or metastatic squamous-cell carcinoma of the head and neck (SPECTRUM): an open-label phase 3 randomised trial. Lancet Oncol. 2013, 14, 697-710.

[8] Kondo, N.; Tsukuda, M.; Ishiguro, Y.; Kimura, M.; Fujita, K.; Sakakibara, A.; Takahashi, H.; Toth, G.; Matsuda, H. Antitumor effects of lapatinib (GW572016), a dual inhibitor of EGFR and HER-2, in combination with cisplatin or paclitaxel on head and neck squamous cell carcinoma. Oncol. Rep. 2010, 23, 957-963.

[9] Spector, N. L.; Xia, W.; Burris, H. 3rd; Hurwitz, H.; Dees, E. C.; Dowlati, A.; O'Neil, B.; Overmoyer, B.; Marcom, P. K.; Blackwell, K. L.; et al. Study of the biologic effects of lapatinib, a reversible inhibitor of ErbB1 and ErbB2 tyrosine kinases, on tumor growth and survival pathways in patients with advanced malignancies. J. Clin. Oncol. 2005, 23, 2502-2512.

[10] Gandhi, M. D.; Agulnik, M. Targeted treatment of head and neck squamous-cell carcinoma : potential of lapatinib. Onco Targets Ther. 2014, 7, 245-251.

[11] Ray-Coquard, I.; Weber, B.; Cretin, J.; Haddad-Guichard, Z.; Levy, E.; Hardy-Bessard, A. C.; Gouttebel, M. C.; Geay, J. F.; Aleba, A.; Orfeuvre, H. et al. Gemcitabine-oxaliplatin combination for ovarian cancer resistant to taxane-platinum treatment: a phase II study from the GINECO group. Br. J. Cancer 2009, 100, 601-607.

[12] Shah, M. A.; Schwartz, G. K. The relevance of drug sequence in combination chemotherapy. Drug Resist. Updat. 2000, 3, 335-356.

[13] Chou, T. C. Drug combination studies and their synergy quantification using the chou-talalay method. Cancer Res. 2010, 70, 440-446. 
[14] Barnham, K. J.; Djuran, M. I.; Murdoch, P. S.; Ranford, J. D.; Sadler, P. J. Ring-Opened adducts of the anticancer drug carboplatin with sulfur amino acids. Inorg. Chem. 1996, 35, 1065-1072.

[15] Al-Eisawi, Z.; Beale, P.; Chan, C.; Yu, J. Q.; Huq, F. Carboplatin and oxaliplatin in sequenced combination with bortezomib in ovarian tumor models. J. Ovarian Res. 2013, 6, 78 DOI: $10.1186 / 1757-2215-6-78$.

[16] Miyoshi, N.; Mišík, V.; Riesz, P. Sonodynamic Toxicity of Gallium-Porphyrin Analogue ATX-70 in Human Leukemia Cells. Radiat. Res. 1997, 148, 43-47.

[17] Miyoshi, N.; Tuziuti, T.; Yasui, K.; Iida, Y.; Shimizu, N.; Riesz, P.; Sostaric, J. Z. Ultrasound-induced cytolysis of cancer cells is enhanced in the presence of micron-sized alumina particles. Ultrason. Sonochem. 2008, 15, 881-890.

[18] Tuziuti, T.; Yasui, K.; Sivakumar, M.; Iida, Y.; Miyoshi, N. Correlation between acoustic cavitation noise and yield enhancement of sonochemical reaction by particle addition. $J$. Phys. Chem. A 2005, 109, 4869-4872.

[19] Overholt, B. F.; Panjehpour, M. Photodynamic therapy for Barrett's esophagus: follow-up in 100 patients. Gastrointest. Endosc. 1999, 49, 1-7.

[20] Grant, W. E.; Hopper, C.; Speight, P. M.;Macrobert, A. J.; Bown, S. G. .Photodynamic therapy of malignant and premalignant lesions in patients with 'field cancerization' of the oral cavity. J. Laryngol. Otol. 1993, 107, 1140-1145.

[21] Fan K. F; Hopper C.; Speight P. M.; Buonaccorsi G.; MacRobert A. J.; Bown S. G. Photodynamic therapy using 5-aminolevulinic acid for premalignant and malignant lesions of the oral cavity. Cancer 1996, 78, 1374-1383.

[22] Jerjes, W.; Hamdoon, Z.; Hopper, C. Photodynamic therapy in the management of potentially malignant and malignant oral disorders. Head Neck Oncol. 2012, 4, 16.

[23] Paiva, M. B.; Saxtonb, R. E.; Blackwella, K. E.; Buechlerc, P.; Cohena, A.; Liuc, C. D.; Calcaterraa, T. C.; Ward, P. H.; Dan, J.; Castro, D. J. Combined cisplatinum and laser thermal therapy for palliation of recurrent head and neck tumors. Diagn. Ther. Endosc. 2000, 6, 133-140.

[24] Civantos, F. Photodynamic therapy for head and neck lesions in the subtropics. J. Natl. Compr. Canc. Netw. 2012, 10 (Suppl 2), 65-68.

[25] Hopper, C. Photodynamic therapy: a clinical reality in the treatment of cancer. Lancet Oncol. 2000, 1, 212-219.

[26] Sunar, U. Monitoring photodynamic therapy of head and neck malignancies with optical spectroscopies. World J. Clin. Cases 2013, 1, 96-105.

[27] Lu, Z. Y.; Sun, Z. Y.; Li, Z. S.; An, L. J. Stability of two-dimensional tessellation ice on the hydroxylated beta-cristobalite (100) surface. J. Phys. Chem. B. 2005, 109, 5678-5683.

[28] Thomalla, M.; Tributshch, H. Photosensitization of nanostructured $\mathrm{TiO}_{2}$ with $\mathrm{WS}_{2}$ quantum sheets. J. Phys. Chem. B, 2006, 110, 12167-12171.

[29] Li, Y.; Li, X.; Li, J.; Yin, J. Photocatalytic degradation of methyl orange by $\mathrm{TiO}_{2}$-coated activated carbon and kinetic study. Water Res. 2006, 40, 1119-1126.
[30] Popov, A. P.; Lademann, J.; Priezzhev, A. V.; Myllylä, R. Effect of size of $\mathrm{TiO}_{2}$ nanoparticles embedded into stratum corneum on ultraviolet-A and ultraviolet-B sun-blocking properties of the skin. J. Biomed. Opt. 2005, 10, 064037.

[31] Zhao, W.; Chen, C.; Ma, W.; Zhao, J.; Wang, D.; Hidaka, H.; Serpone, N. et al. Efficient photoinduced conversion of an azo dye on hexachloroplatinate(IV)-modified $\mathrm{TiO}_{2}$ surfaces under visible light irradiation-A photosensitization pathway. Chemistry 2003, 9, 3292-3299.

[32] van der Molen, R. G.; Garssen, J.; de Klerk, A.; Claaus, F. H.; Norval, M.; van Loveren, H,; Koerten, H. K.; Mommaas, A. M. Application of a systemic herpes simplex virus type 1 infection in the rat as a tool for sunscreen photoimmunoprotection studies. Photochem. Photobiol. Sci. 2002, 1, 592-596.

[33] Rouabhia, M.; Mitchell, D.L.; Rhainds, M.; Claveau, J.; Drouin, R. A. Physical sunscreen protects engineered human skin against artificial solar ultraviolet radiation-induced tissue and DNA damage. Photochem. Phtobiol. Sci. 2002, 1, $471-477$.

[34] Dai, Q.; Rabani, J. Photosensitization of nanocrystalline $\mathrm{TiO}_{2}$ films by pomegranate pigments with unusually high efficiency in aqueous medium. Chem. Commun. (Camb.) 2001, 21, 2142-2143.

[35] Li, F. B.; Li, X. Z. The enhancement of photodegradation efficiency using Pt- $\mathrm{TiO}_{2}$ catalyst. Chemosphere 2002, 48, $1103-1111$.

[36] Peter, L. M.; Riley, D. J.; Tull E. J.; Wijayantha, K. G. Photosensitization of nanocrystalline $\mathrm{TiO}_{2}$ by self-assembled layers of CdS quantum dots. Chem. Commun. (Camb) 2002, $21,1030-1031$.

[37] Xu, S.;Shen, J.; Chen, S.; Zhang, M.; Shen, T. Active oxygen species $\left({ }^{1} \mathrm{O}_{2}, \mathrm{O}_{2}{ }_{-}\right)$generation in the system of $\mathrm{TiO}_{2}$ colloid sensitized by hypocrellin B. J. Photochem. Photobiol. B. 2002, 67, 64-70.

[38] Wu, T.; Xu, S.; Shen, J.; Chen, S.; Zhang, M.; Shen, T.EPR investigation of the free radicals generated during the photosensitization of $\mathrm{TiO}_{2}$ colloid by hypocrellin B. Free Raic. Res. 2001, 35, 137-143.

[39] Galindo, C.; Jacques, P.; Kalt, A. Photooxidation of the phenylazonapthol AO20 on $\mathrm{TiO}_{2}$ : kinetic and mechanistic investigations. Chemosphere 2001, 45, 997-1005.

[40] Kuo, W. S. ; Ho, P. H. Solar photocatalytic decolorization of methylene blue in water. Chemosphere 2001, 45, 77-83.

[41] Gholamkhass, B.; Koike, K.; Negishi, N.; Hori, H.; Takeuchi, K. Synthesis and characterization of ruthenium(II) molecular assemblies for photosensitization of nanocrystalline $\mathrm{TiO}_{2}$ : utilization of hydroxyl grafting mode. Inorg. Chem. 2001, 40 756-765.

[42] Hancock-Chen, T.; Scaiano, J. C. Enzyme inactivation by $\mathrm{TiO}_{2}$ photosensitization. J. Photochem. Photobiol. B. 2000, 57, 193-196.

[43] Wang, Cy.; Liu, Cy.; Wang, Y.; Shen, T. Spectral characteristics and photosensitization effect on $\mathrm{TiO}_{2}$ of fuorescein in AOT reversed micelles. J. Colloid Interface Sci. 1998, 197, 126-132. 
[44] Wang, Cy.; Groenzin, H.; Shultz, M. J. Comparative Study of Acetic Acid, Methanol, and Water Adsorbed on Anatase $\mathrm{TiO}_{2}$ Probed by Sum Frequency Generation Spectroscopy. J. Am. Chem. Soc. 2005, 127, 9736-9744.

[45] Asahi, R.; Morikawa, T.; Ohwaki, T.; Aoki, K.; Taga, Y. Visible-light photocatalysis in nitrogen-doped titanium oxides. Science 2001, 293, 269-271.

[46] Franke, R.; Franke, C. Model reactor for photocatalytic degradation of persistent chemicals in ponds and waste water. Chemosphere 1999, 39, 2651-2659.

[47] Miyoshi, N.; Ogasawara, T.; Nakano, K.; Tachihara, R.; Kaneko, S.; Sano, K.; Fukuda, M.; Hisazumi, H. An application of fluorescence analysis in tumor tissue. In Proceedings of 2nd International ALA Symposium, Fukuoka, Japan, 2005, pp 11-16.

[48] Miyoshi, N.; Tuziuti, T.; Yasui, K.; Iida, Y.; Ito, Y. Analysis of $\mathrm{Ti}_{3}\left(\mathrm{PO}_{4}\right)_{4}$ Particles Combined with 5-ALA by Counter Current Chromatography to modify Photo- and Sono-sensitizers. In Proceedings of the 4th International Symposium of Countercurrent Chromatography (CCC), Bethesda, MD, USA, 2006, p 35.

[49] Miyoshi, N.: Combined therapy and new nano-drug development for PDT. In Proceedings of the 14th World Congress for the International Photodynamic Association, Seoul, Korea, 2013, p 12.

[50] Bihari, P.; Vippola, M.; Schultes, S.; Praetner, M.; Khandoga, A. G.; Reichel. C. A.; Coester, C.; Tuomi, T.; Rehberg, M.; Krombach, F. Optimized dispersion of nanoparticles for biological in vitro and in vivo studies. Part. Fibre Toxicol. 2008, 5, 1-14, DOI: 10.1186/CET17438977.

[51] Murdock, R. C.; Braydich-Stolle, L.; Schrand, A. M.; Schlager, J. J.; Hussain, S. M. Characterization of nanomaterial dispersion in solution prior to in vitro exposure using dynamic light scattering technique. Toxicol. Sci. 2008, 101, 239-53.

[52] Ito, Y,; Bowman, R.L. Countercurrent Chromatography: liquid-liquid partition chromatography without solid support. Science 1970, 167, 281-283.

[53] Tanimura, T.; Pisano, J. J.; Ito, Y.; Bowman, R. L. Droplet countercurrent chromatography. Science 1970, 169, 54-56.

[54] Ito, Y.; Bowman, R. L. Countercurrent chromatography with flow-through coil planet centrifuge. Science 1971, 173, 420-422.

[55] Spinks, J. W. T.; Woods, T. J. An introduction to radiation chemistry, New YorK, Wiley Interscience, 1990.

[56] Kinoshita, H.; Miyoshi, N.; Ogawa, T.; Kitagawa, T.; Itoh, H.; Sano, K. Phosphate mapping of sialoliths with Raman microspectroscopy. J. Raman Spectrosc. 2008, 39, 349-353.
[57] Kinoshita, H.; Miyoshi, N.; Ogasawara, T.; Sano, K. Functional mapping of caries enamel of a human teeth with Raman microspectroscopy. J. Raman Spectrosc. 2008, 39, 655-660.

[58] Peng, Q.; Warloe, T.; Moan, J.; Heyerdahl, H.; Steen, H. B.; Nesland, J. M.; Giercksky, K. E. Distribution of 5-aminolevulinic acid-induced porphyrins in noduloulcerative basal cell carcinoma. Photochem. Photobiol. 1995, 62(5), 906-913.

[59] Ferrari, M. Cancer nanotechnology: opportunities and challenges, Nat. Rev. Cancer. 2005, 5, 161-171.

[60] Thevenot, P.; Cho, J.; Wavhal, D.; Timmons, R.B.; Tang, L. Surface chemistry influences cancer killing effect of $\mathrm{TiO}_{2}$ nanoparticles. Nanomed. Nanotechnol. Biol. Med. 2008, 4, 226-236.

[61] Mazurkova, N.A.; Spitsyna, Yu. E.; Shikina, N. V.; Ismagilov, Z. R.; Zagrebel'nyi, S. N.; Ryabchikova, E. I. Interaction of titanium dioxide nanoparticles with influenza virus. Nanotechnol. Russ. 2011, 5, 417-420.

[62] Tsuang, H. Y.; Sun, J. S.; Huang, Y. C.; Lu, C. H.; Chang, W. H.; Wang C. C. Studies of photokilling of bacteria using titanium dioxide nanoparticles. Artif. Organs 2008, 32, $167-174$.

[63] Paunesku, T.; Rajh, T.; Wiederrecht, G.; Maser, J.; Vogt. S.; Stojicevic, N.; Protic, M.; Lai, B.; Oryhon, J.; Thurnauer, M.; et al. Biology of $\mathrm{TiO}_{2}$-oligonucleotide nanocomposites. Nat. Mater. 2003, 2, 343-346.

[64] Paunesku, T.; Vogt, S.; Lai, B.; Maser, J.; Stojicevic, N.; Thurn, K. T.; Osipo, C.; Liu, H.; Legnini, D.; Wang, Z.; et al. Intracellular distribution of $\mathrm{TiO}_{2}-\mathrm{DNA}$ oligonucleotide nanoconjugates directed to nucleolus and mitochondria indicates sequence specificity. Nano Lett. 2007, 7, 596-601.

[65] Landsiedel, R.; Ma-Hock, L.; Kroll, A.; Hahn, D.; Schnekenburger, J.; Wiench, K.; Wohlleben, W. Testing metal-oxide nanomaterials for human safety. Adv. Mater. 2010, 22, 2601-2627.

[66] Nel, A.; Xia, T.; Madler, L.; Li, N. Toxic potential of materials at the nanolevel. Science 2006, 311, 622-627.

[67] Wang, J. X.; Zhou, G. Q.; Chen, C. Y.; Yu, H. W.; Wang, T. C.; Ma, Y. M.; Jia, G.; Gao, Y.; Li, B.; Sun J.; et al. Acute toxicity and biodistribution of different sized titanium dioxide particles in mice after oral administration. Toxicol. Lett. 2007, 168, 176-185.

[68] Duan, Y.; Liu, J.; Ma, L.; Li, N.; Liu, H.; Wang, J.; Zheng, L.; Liu, C.; Wang, X.; Zhao, X.; et al. Toxicological characteristics of nanoparticulate anatase titanium dioxide in mice, Biomaterials 2010, 31, 894-899. 